\section{Concerns regarding sinking of South Korean warship}

In a News story (Nature 466, 302-303; 2010), you discuss Seung-Hun Lee's analysis of the official South Korean report on the sinking of the warship Cheonan on 26 March (S.-H. Lee and P. Yang, preprint at http://arxiv. org/abs/1006.0680; 2010). In my opinion (I am independent and not politically connected), neither this work nor the report from South Korea's Joint Investigation Group (JIG) seems sufficiently technically convincing to explain the event fully (see also go.nature.com/aS7Eoz; go.nature. com/JQLzcU and go.nature. com/7bpWYL; in Korean).

It is reasonable to assume that all navies now use some form of aluminized explosive for their torpedoes. Good simulation experiments are only feasible if they use the same aluminized explosive as the torpedo in question; however, it is unlikely that the explosive's producers will identify themselves in this case, let alone make it available. Assuming it was not an accident, only the party responsible for sinking the Cheonan can carry out the proper simulation experiments.

Having related knowledge and experience of the subject, I find that the critical weakness of Lee's simulation experiment is that it didn't use explosive; also, I believe that Panseok Yang's analytical (electron-dispersive spectroscopy) data were not properly corrected so should not be compared with the JIG's uncorrected data. As for the JIG experiment, it does not reproduce the actual conditions of an explosion. It used 15 grams of sealed explosive in sea water (compare with the 200-300 kilograms in the suspected torpedo), producing an explosive pressure of less than 1,000 atmospheres; however, the temperature and pressure inside a torpedo just before it explodes are likely to reach up to $5,000^{\circ} \mathrm{C}$ and 200,000 atmospheres, which will oxidize almost all of the aluminium in the explosive.

Even without simulation experiments, it should still be possible to determine whether the deposits from two different sources (the ship and the torpedo) are the same material, and whether they contain the forms of aluminium used in explosives.

My concern is whether the currently available data from the deposits have been correctly sampled and interpreted. A more comprehensive chemical and physical analysis should provide more accurate and useful information.

Kwang Sup Kim Andover,

Massachusetts, USA

\section{Problems in Turkish science run deeper than petty disputes}

The problems facing palaeoanthropologists in Turkey go beyond petty disputes between colleagues (Nature 466, 176-178; 2010). They stem from the political and cultural forces generated by the country's 1980 political coup.

The Turkish education system seems to have been infiltrated by the post-coup government's religious and nationalist agenda. Innovative research is inhibited by the restrictive nature of the academic material that students may study.

Turkish palaeoanthropologists have sought to overcome such limitations by collaborating with foreign scientists. But this often disadvantages Turkish scholars: although they supply the raw materials, it is the foreign scientists who have the necessary methods, techniques, equipment and language to assess and publish fossil findings. Few palaeoanthropological papers are published by Turkish scientists alone.

In striving to compete in the international sphere, Turkish palaeoanthropologists should not overlook the need to establish a solid science base at home. By giving priority to their own Turkish-led research, they will be helping the next generation to benefit from their knowledge and experience.

Ferhat Kaya Ahi Evran University, Kırșehir 40100, Turkey e-mail:paleolife@yahoo.com

\section{Press release and media distort complex message}

Five days after publication of Heike Vester and Marc Timme's Correspondence on the potential environmental damage by Chile's salmon farms (Nature 465, 869; 2010), the Max Planck Society in Munich posted a press release on the 'Environmental scandal in Chile' (go.nature.com/EnJh9B). This gave rise to media reports that should remind scientists of their responsibility to be able to back up their comments and opinions.

The two documents generated newspaper and magazine articles globally (we analysed 13 sources; available from the authors). Most of these mixed up extracts from both texts and attributed statements to Vester and Timme's "report published in the journal Nature" that were not in the Correspondence. The news articles did not mention caveats of the salmon industry worldwide: uncertain facts, disputed values, high stakes and urgent decisions.

It is uncertainties in available information that undermine evaluations of ecosystem health, rather than the potential ecological and social risks associated with the industry at large. The management of uncertainty by scientists rests on high-quality, peer-reviewed data. Bypassing that process risks compromising the credibility of science and scientists.

As a result of Nature's position as an interlocutor of the science-society interface, this case fits the concept of 'postnormal' uncertainty, in which the science is forced to play out under heavy social and political pressure - as in climate change and overexploitation of natural resources. But science still has a duty to provide sound information so that society can find ways to adapt to a changing world.

Víctor H. Marín, Luisa E. Delgado, Antonio Tironi Facultad de Ciencias, Universidad de Chile, Las Palmeras 3425, Ñuñoa, Santiago, Chile e-mail:vmarin@antar.uchile.cl

Editorial note: Correspondence items are short opinion pieces; they are neither peer reviewed nor original research. See author guidelines at go.nature.com/cMCHno.

\section{Difference between interim and final acid-rain reports}

William Nierenberg's relatives disagree with our description of his role in the acid-rain debate in the early 1980s (Nature 466, $435 ; 2010$ ). But their supporting evidence is a quote from The New York Times that is based on an interim report on acid rain, not on the final one.

We maintain that Nierenberg worked with the White House Office of Science and Technology to weaken the final report on acid rain (Nature 465, 686-687; 2010), despite the consensus of the peerreview panel - articulated in the interim report - that acid rain was a serious threat. Historical documents from the White House and from Nierenberg's own papers in the archives of the Scripps Institution of Oceanography (for details, see N. Oreskes and E. M. Conway Merchants of Doubt; Bloomsbury Press, 2010) show how this was accomplished, and reveal the concern of other panel members when they discovered what had happened.

Naomi Oreskes University of California, San Diego, California 92093, USA e-mail:naoreskes@ucsd.edu Erik M. Conway California Institute of Technology, Pasadena, California 91109, USA 